\title{
Influence of Culture Conditions on the Physiology and Composition of Trichoderma aureoviride
}

\author{
By DAVID E. PITT $\dagger$ AND ALAN T. BULL* $\ddagger$ \\ Department of Applied Biology, University of Wales Institute of Science and Technology, \\ King Edward VII Avenue, Cardiff CF1 3NU, Wales
}

(Received 26 October 1981)

\begin{abstract}
The biomass and residual limiting substrate profiles of chemostat grown Trichoderma aureoviride were typical of carbon- and of nitrogen-limited micro-organisms. Maintenance energy requirements partly accounted for the discrepancy between observed and predicted values of biomass concentration at low dilution rates under glucose limitation. At such low dilution rates the fungal mycelium became differentiated and sporulation occurred. The steady state glucose concentrations in glucose-limited cultures were higher than those predicted by chemostat theory; much closer agreement between observed and predicted values was achieved when a corrected $\mu_{\max }$ term (Pitt \& Bull, 1982 $a$ ) was used to calculate the residual glucose concentration. The measured growth parameters $\left(\mu_{\max }, \mu_{\min }, K_{\mathrm{s}}, Y\right.$ and $\left.m\right)$ for $T$. aureoviride had values similar to those reported for other species of filamentous fungi. The biomass concentration of fed-batch cultures increased linearly with time but glucose supplied at a rate three times higher than the maintenance requirement was insufficient to prevent sporulation. Mycelial RNA and protein concentrations increased with increasing dilution rate and were 30 and $40 \%$ lower under nitrogen limitation than under carbon limitation. DNA concentration was not influenced by dilution rate. The molar ratio of $\mathrm{RNA}: \mathrm{Mg}^{2+}: \mathrm{K}^{+}$was 8:1:8 and was dilution rate independent. Only two polyamines, spermine and spermidine, were detected in $T$. aureoviride; they increased in concentration and proportion of the biomass as the dilution rate was raised but there was no evidence of their functional interchange ability with $\mathrm{Mg}^{2+}$ ions as reported for other fungi.
\end{abstract}

\section{INTRODUCTION}

Descriptions of the mycelial growth of fungi have been derived, with only very few exceptions, from studies of batch cultures either in liquid or on solid media. The use of continuous flow culture techniques to explore fungal physiology has been slight (Bull \& Trinci, 1977) and even experimental tests of chemostat theory with these organisms are incomplete. Furthermore, understanding of the phenotypic variability of fungal chemistry and metabolism remains in a primitive state in comparison to our knowledge of bacteria.

This paper reports on studies of fungal behaviour in chemostat culture and attempts to refine the mathematical description of mycelial growth by taking into account a true specific growth rate $\left(\mu_{\mathrm{h}}\right)$ based on the proportion of actively growing hyphae in the population (Pitt \& Bull, 1982a). These analyses have been made with a wild-type strain of Trichoderma aureoviride and details of its macromolecular and cationic composition are also included.

\section{METHODS}

Organism and culture conditions. A strain of Trichoderma aureoviride Rifai agg. (Rifai, 1969; isolated by Chesters \& Bull, 1963) was used throughout this study. Continuous culture of the fungus was carried out in a 3.01

† Present address: Biotechnology Australia Pty. Ltd., POB 109, Petersham North, NSW, Australia 2049.

$\ddagger$ Present address: Biological Laboratory, University of Kent, Canterbury, Kent CT2 7NJ, U.K. 
magnetically stirred fermenter (LH Engineering, Stoke Poges, Bucks) (Pitt \& Bull, 1982a). The working volume, temperature, $\mathrm{pH}$, agitation and aeration rates were maintained at $2.81,30^{\circ} \mathrm{C}, 4.5,1000 \mathrm{rev} . \mathrm{min}^{-1}$ and 2.81 $\min ^{-1}$, respectively. Fed-batch cultures were established by reducing the volume of a steady state (dilution rate, $D$ $=0.10 \mathrm{~h}^{-1}$ ) culture to $1.5 \mathrm{l}$, maintaining the operating conditions as stated above and feeding the remaining culture at a slow rate (about $21 \mathrm{ml} \mathrm{h}^{-1}$ ) with complete medium containing $30 \mathrm{~g}$ glucose $\mathrm{1}^{-1}$ in order to provide the desired input rate of glucose. The feed rate was calculated such that the initial supply of glucose to the culture was three times the maintenance ration [i.e. $0.060 \mathrm{~g}$ glucose (g biomass) $)^{-1} \mathrm{~h}^{-1}$ ]. This procedure was similar to that used by Bainbridge et al. (1971) to establish non-growing maintained and autolysing cultures of Aspergillus nidulans.

The chemostat was inoculated with a suspension of filamentous mycelia (about $150 \mathrm{ml}$ ) grown from a spore inoculum in a magnetically stirred flask culture. The growth media contained $\left(\mathrm{g} \mathrm{l}^{-1}\right)$ : (a) for glucose limitation glucose, 10; $\left(\mathrm{NH}_{4}\right)_{2} \mathrm{SO}_{4}, 5 \cdot 0 ; \mathrm{K}_{2} \mathrm{HPO}_{4}, 0.75 ; \mathrm{Na}_{2} \mathrm{HPO}_{4}, 0.75$; trace elements (Carter \& Bull, 1969), $60 \mathrm{ml} \mathrm{l}^{-1}$ of a $\times 20$ strength stock solution; (b) for ammonia limitation - as above except glucose, 25 and $\left(\mathrm{NH}_{4}\right)_{2} \mathrm{SO}_{4}, 2 \cdot 0$. The trace element stock solution contained: $\mathrm{Na}_{2}$ EDTA. $2 \mathrm{H}_{2} \mathrm{O}, 12 \mathrm{~g} ; \mathrm{MgSO}_{4} \cdot 7 \mathrm{H}_{2} \mathrm{O}, 5 \mathrm{~g} ; \mathrm{CaCl}_{2} 1.0 \mathrm{~g} ; \mathrm{ZnSO}_{4} .7 \mathrm{H}_{2} \mathrm{O}$, $0.4 \mathrm{~g} ; \mathrm{MnSO}_{4} .4 \mathrm{H}_{2} \mathrm{O}, 0.4 \mathrm{~g} ; \mathrm{CuSO}_{4} .5 \mathrm{H}_{2} \mathrm{O}, 0.1 \mathrm{~g} ; \mathrm{FeSO}_{4} .7 \mathrm{H}_{2} \mathrm{O}, 2.0 \mathrm{~g}$ (plus $0.5 \mathrm{ml}$ concentrated $\mathrm{H}_{2} \mathrm{SO}_{4}$ ); $\mathrm{Na}_{2} \mathrm{SO}_{4}, 8 \cdot 5 \mathrm{~g} ; \mathrm{Na}_{2} \mathrm{MoO}_{4} \cdot 2 \mathrm{H}_{2} \mathrm{O}, 0.1 \mathrm{~g}$; distilled water, 1 litre. The $\mathrm{pH}$ was controlled by the automatic addition of either $2 \mathrm{M}-\mathrm{KOH}$ or $0.75 \mathrm{M}-\mathrm{H}_{2} \mathrm{SO}_{4}$.

Mycelia were harvested from the fermenter via a spring-loaded, rapid sample device (Pitt \& Bull, 1982 $b$ ) which enabled approximately $20 \mathrm{ml}$ of culture to be collected in a plastic vial containing $2 \mathrm{ml}$ perchloric acid (30\% v/v) in less than $1 \mathrm{~s}$.

Analytical procedures. Biomass concentrations were determined in duplicate on $10 \mathrm{ml}$ samples of culture passed through $0.45 \mu \mathrm{m}$ pore filters, washed with isotonic saline and dried to constant weight overnight at $105^{\circ} \mathrm{C}$. Glucose was assayed with a commercial glucose oxidase kit (Boehringer Corporation) and, during ammonialimited cultivation, the residual ammonia concentration was determined by an indophenol blue method (Allen $e t$ al., 1974).

Mycelial samples for DNA $(10 \mathrm{ml})$ and RNA $(5 \mathrm{ml})$ determinations were extracted with $\mathrm{HClO}_{4}(30 \%$, v/v) and assayed by the diphenylamine and orcinol procedures, respectively (Herbert et al., 1971). All samples were analysed soon after harvesting from the chemostat in order to avoid degradation during storage.

Protein was determined in fresh samples $(0.5 \mathrm{ml}$ and $1.0 \mathrm{ml})$ of the culture using the biuret method and bovine serum albumin as a standard (Herbert et al., 1971). Mycelial magnesium was extracted with ice-cold $20 \%$ (v/v) $\mathrm{HClO}_{4}$ according to the procedure of Herbert et al. (1971). A further extraction was made at $70^{\circ} \mathrm{C}$ in order to ensure maximum release of structurally bound magnesium. Quantitative extraction of potassium from micro-organisms is difficult because of losses resulting from leakage during harvesting. Consequently, the intracellular potassium concentration was determined as the difference between that in the biomass plus supernatant (i.e. whole culture) and that in the supernatant alone, as described by Herbert et al. (1971). The final extracts for potassium and magnesium assays were diluted with $0.2 \%(\mathrm{w} / \mathrm{v})$ aqueous lanthanum chloride in order to minimize chemical interference during subsequent analysis in an SP190 atomic absorption spectrophotometer (Pye Unicam).

Polyamines were extracted from the mycelium by the procedures described previously (Bushell \& Bull, 1974) and separated on silica gel plates (Kieselgel $\mathrm{G}$ type 60; Merck). The development of chromatograms in the ethyl acetate/cyclohexane $(2: 3, \mathrm{v} / \mathrm{v})$ of Dion \& Herbst (1970) failed to resolve cadavarine and putrescine; the best separation of reference polyamines was achieved with ethyl acetate/petroleum ether (b.p. $\left.40-60^{\circ} \mathrm{C}\right)(3: 5, \mathrm{v} / \mathrm{v})$. Eluted polyamines were assayed spectrofluorimetrically (SFR100 ratio recording fluorimeter. Baird Atomic, Braintree, Essex) using an excitation wavelength of $350 \mathrm{~nm}$ (slit $5 \mathrm{~nm}$ ) and emission wavelength of $490 \mathrm{~nm}$ (slit 10 $\mathrm{nm}$ ). This method gave linear calibrations of cadavarine, putrescine, spermine and spermidine over the range 1 to $30 \mathrm{nmol} \mathrm{mi}^{-1}$.

Calculations. The maximum specific growth rates of glucose-limited and ammonia-limited $T$. aureoviride were determined by a washout method (Jannasch, 1969). A plot of $\ln x$ against time $(t)$ was analysed by linear regression to derive the gradient, which is equal to $\left(\mu_{\max }-D\right)$.

The maintenance energy coefficient for glucose $(m)$ and the specific maintenance rate $(a)$ were calculated according to the method of Pirt (1975) using the specific rate of glucose consumption $(q)$ in glucose-limited chemostat cultures. A plot of $q$ against $D$ gives $m$ as the intercept and the inverse of the gradient is equivalent to the true growth yield, $Y_{\mathrm{G}} ; a$ is the product of $m \cdot Y_{\mathrm{G}}$.

Theoretical steady state values for biomass $(\bar{x})$ and limiting substrate $(\bar{s})$ concentrations were calculated using the equations of Pirt (1975, p. 42) and took account of the maintenance energy requirement.

\section{RES ULT S}

\section{Kinetics of carbon-limited and ammonia-limited growth}

The observed and calculated values for steady state biomass and residual substrate concentrations in glucose-limited cultures are presented in Fig. 1. The biomass concentration 


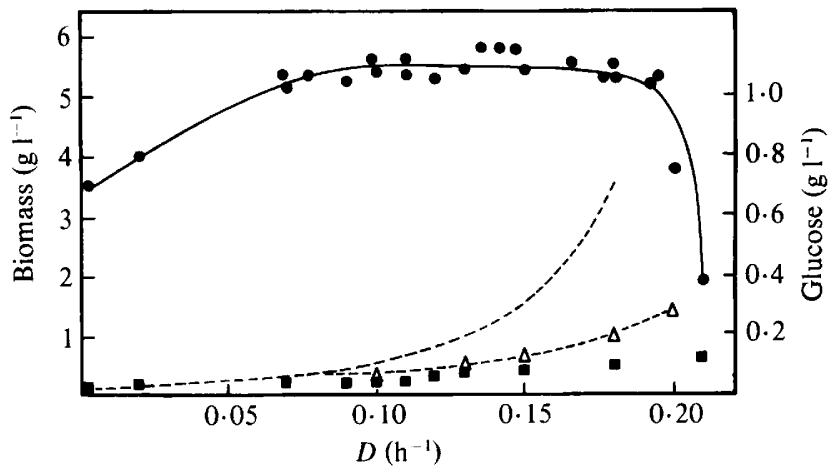

Fig. 1. Observed and calculated values of biomass and growth-limiting substrate concentrations during glucose-limited culture of Trichoderma aureoviride: observed biomass ( $)$; calculated biomass -; observed glucose ( $\square$ ); calculated glucose - - ; calculated glucose concentration using a corrected value for $\mu_{\max }$ (see Discussion) $(\triangle---\triangle)$.

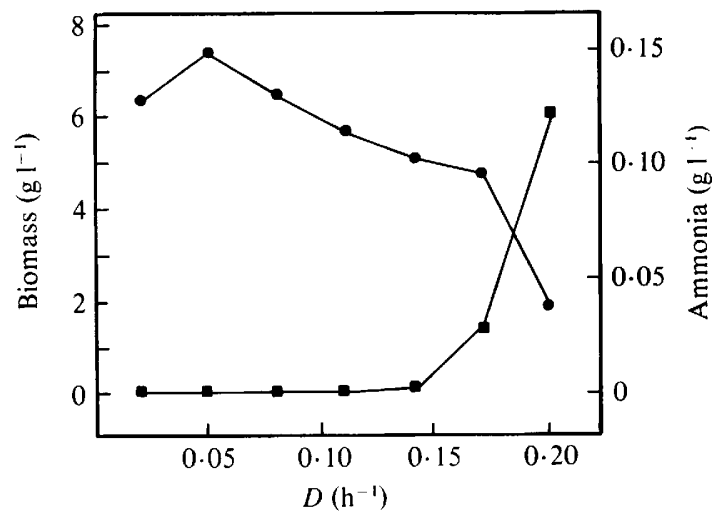

Fig. 2. Observed concentrations of biomass ( $)$ and ammonia ( $\square$ ) during ammonia-limited culture of Trichoderma aureoviride.

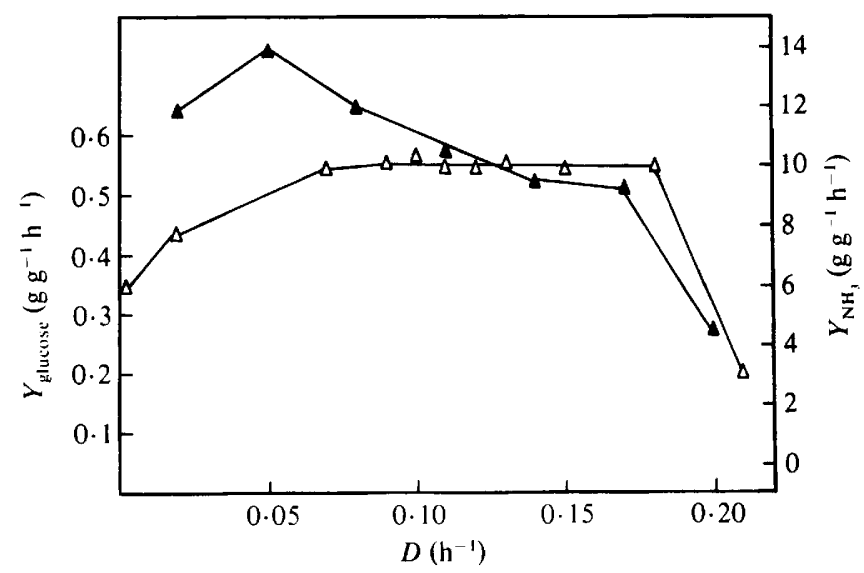

Fig. 3. Experimental growth yields of Trichoderma aureoviride: $Y_{\text {gluc }}$, glucose-limited growth $(\triangle)$; $Y_{\mathrm{NH},}$, ammonia-limited growth $(\mathbf{\Delta})$. 
Table 1. Growth parameters for glucose- and ammonia-limited growth of Trichoderma aureoviride

The following nomenclature is used in this paper: $\mu_{\max }$, maximum specific growth rate; $\mu_{\min }$, minimum specific growth rate; $D_{\text {crit }}$, critical dilution rate; $Y$, growth yield; $Y_{\mathrm{G}}$, true or maximum growth yield; $K_{\mathrm{s}}$, limiting substrate saturation constant; $m$, maintenance energy coefficient; $a$, specific maintenance rate.

\begin{tabular}{|c|c|c|}
\hline \multirow[b]{2}{*}{ Parameter } & \multicolumn{2}{|c|}{ Nutrient limitation } \\
\hline & Glucose & Ammonia \\
\hline$\mu_{\max }$ & $0.22 \mathrm{~h}^{-1}$ & $0.20 \mathrm{~h}^{-1}$ \\
\hline$\mu_{\min }{ }^{*}$ & $0.02-0.04 \mathrm{~h}^{-1}$ & $0.02-0.04 \mathrm{~h}^{-1}$ \\
\hline$D_{\text {crit }}^{\dagger}$ & $0 \cdot 218 \mathrm{~h}^{-1}$ & $0.195 \mathrm{~h}^{-1}$ \\
\hline$Y_{\text {gluc }}^{\text {ctit }}$ & $0.54 \mathrm{~g}_{\text {biomass } \mathrm{g}^{-1}}$ & - \\
\hline$Y_{\mathrm{G}}^{\mathrm{gic}}$ & $0.64 \mathrm{~g}$ biomass $\mathrm{g}^{-1}$ & - \\
\hline$Y_{\mathrm{NH}_{3}}^{\mathrm{G}} \ddagger$ & - & 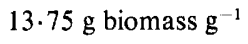 \\
\hline$K_{\mathrm{S} \text { (gluc) }}$ & $0.102 \mathrm{~g} \mathrm{l}^{-1}$ & - \\
\hline$K_{\mathrm{S}\left(\mathrm{NH}_{3}\right)}$ & - & $0.048 \mathrm{~g} \mathrm{l}^{-1}$ \\
\hline$m^{\sin _{37}}$ & $0.02 \mathrm{~g}$ biomass $\mathrm{g}^{-1} \mathrm{~h}^{-1}$ & - \\
\hline$a$ & $0.038 \mathrm{~h}^{-1}$ & - \\
\hline
\end{tabular}

* Based on morphological differentiation (see Text).

+ Critical dilution rate was calculated from the formula $D_{\text {crit }}=\mu_{\max } \cdot S_{\mathrm{R}} /\left(S_{\mathrm{R}}+K_{\mathrm{S}}\right)$, where $S_{\mathrm{R}}$ is the concentration of growth limiting substrate in the inflowing medium; the observed value for $\mu_{\max }$ (glucose) was used in this calculation.

$\ddagger$ Maximum observed values.

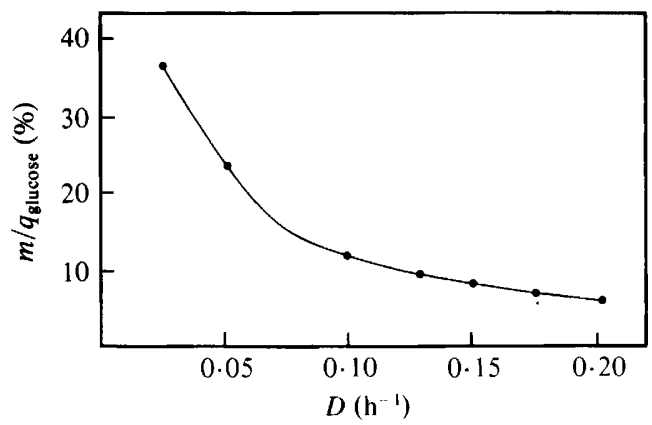

Fig. 4. Proportion ( $\left.m / q_{\text {glucose }}\right)$ of the energy source used by Trichoderma aureoviride for maintenance purposes as a function of dilution rate in a glucose-limited culture.

was reasonably constant over most of the dilution rate range, a situation which was not observed when the fungus was grown under ammonia limitation (Fig. 2). The biomass yield from glucose obtained during glucose-limited growth was constant at about $0.54 \mathrm{~g}$ biomass (g glucose) $)^{-1}$ over most of the dilution rate range which was investigated $\left(0.07\right.$ to $\left.0.18 \mathrm{~h}^{-1}\right)$ (Fig. 3). During ammonia-limited cultivation, the yield of biomass from ammonia showed a linear increase as the dilution rate was lowered from $0.16 \mathrm{~h}^{-1}$ to $0.05 \mathrm{~h}^{-1}\left[Y_{\max }=13.75 \mathrm{~g}\right.$ biomass $\left(\mathrm{g} \mathrm{NH}_{3}\right)^{-1}$; the yield fell at the most extreme dilution rates investigated.

The substrate affinity coefficients for glucose and ammonia and the maintenance energy coefficient are given in Table 1 together with other growth parameters. The minimum specific growth rate $\left(\mu_{\min }\right)$ for $T$. aureoviride was of the order 0.02 to $0.04 \mathrm{~h}^{-1}$, as judged by the criterion of morphological differentiation of the mycelium. At dilution rates below $0.04 \mathrm{~h}^{-1}$ the frequency of mycelial branching, hyphal swelling and vacuolation, increased progressively 


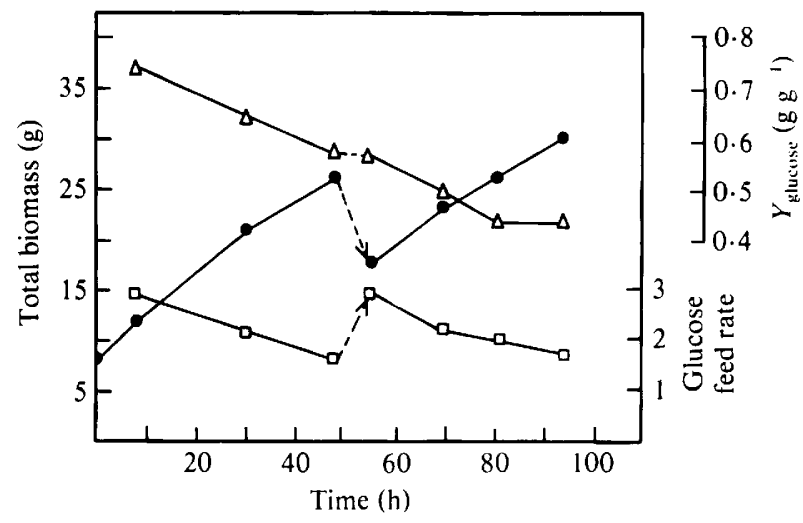

Fig. 5. Fed-batch culture of Trichoderma aureoviride. Biomass (O), yield from glucose $(\triangle)$ and glucose feed rate expressed as a function of the maintenance requirement rate ( $\square$ ). A proportion of the culture was drawn off after $48 \mathrm{~h}$ to enable a further period of fed-batch operation.

and chlamydospore-like structures were constant features of the culture. The proportion of catabolized glucose which was used for maintenance varied as a function of the dilution rate (Fig. 4).

As $D$ approached $\mu_{\max }$ only about $6 \%$ of the glucose consumed was used for maintenance but at the lowest dilution rates examined $\left(0.024 \mathrm{~h}^{-1}\right)$ the maintenance energy requirement was equivalent to $36 \%$ of the catabolized glucose. The proportion of glucose consumed for maintenance purposes rose at a greater rate below a dilution rate of $0.06 \mathrm{~h}^{-1}$ and this coincided with the onset of morphological differentiation.

The behaviour of $T$. aureoviride at low specific growth rates also was studied in fed-batch culture. The addition of glucose to a culture previously growing at $0 \cdot 10 \mathrm{~h}^{-1}$ (see Methods) was calculated to provide the total biomass with, initially, three times its maintenance energy requirement. This rate of addition was sufficient to allow a net increase in the culture biomass (Fig. 5). However, marked morphological differentiation occurred after about $30 \mathrm{~h}$ of fed-batch operation and, although poorly branched, non-autolysed hyphae were present throughout the $96 \mathrm{~h}$ of operation, the culture became progressively more differentiated with time. The presence of thick-walled, birefringent spores was clearly evident after about $48 \mathrm{~h}$. These spores originated as terminal hyphal swellings and from fragmented hyphae and germinated without requiring a prior period of dormancy. Indeed, such spores were often seen to have associated germ tubes during the fed-batch cultivation period and still others were observed to have a short germ tube from which a terminal spore developed. During the course of fed-batch cultivation the biomass yield from glucose decreased linearly with time from about 0.70 to $0.44 \mathrm{~g}$ biomass $(\mathrm{g} \text { glucose })^{-1}$, whereas total biomass showed a linear increase with feed time (Fig. 5).

The rate of supply of glucose corresponded to an initial dilution rate in the fed-batch culture of $0.014 \mathrm{~h}^{-1}$. The quasi-steady state specific growth rate in fed-batch culture can be calculated from the changes in biomass concentration with time (Pirt, 1975) and during the first $48 \mathrm{~h}$ of culture a value of $0.027 \mathrm{~h}^{-1}$ was calculated for $T$. aureoviride; this is equivalent to $12 \% \mu_{\max }$. The biomass yields at this specific growth rate (i.e. $0.027 \mathrm{~h}^{-1}$ ) were very similar for steady state chemostat $\left[0.45 \mathrm{~g}\right.$ biomass (g glucose) ${ }^{-1}$; Fig. 3] and fed-batch $[0.44 \mathrm{~g}$ biomass (g glucose) $)^{-1}$; Fig. 5] culture. As shown in Fig. 1, steady state growth was established at a dilution rate as low as $0.004 \mathrm{~h}^{-1}$. However, at this dilution rate the predominant morphology was unicellular, with many of the spores possessing germ tubes and the biomass yield was reduced to $0.34 \mathrm{~g}$ biomass (g glucose) ${ }^{-1}$ (Fig. 3). 


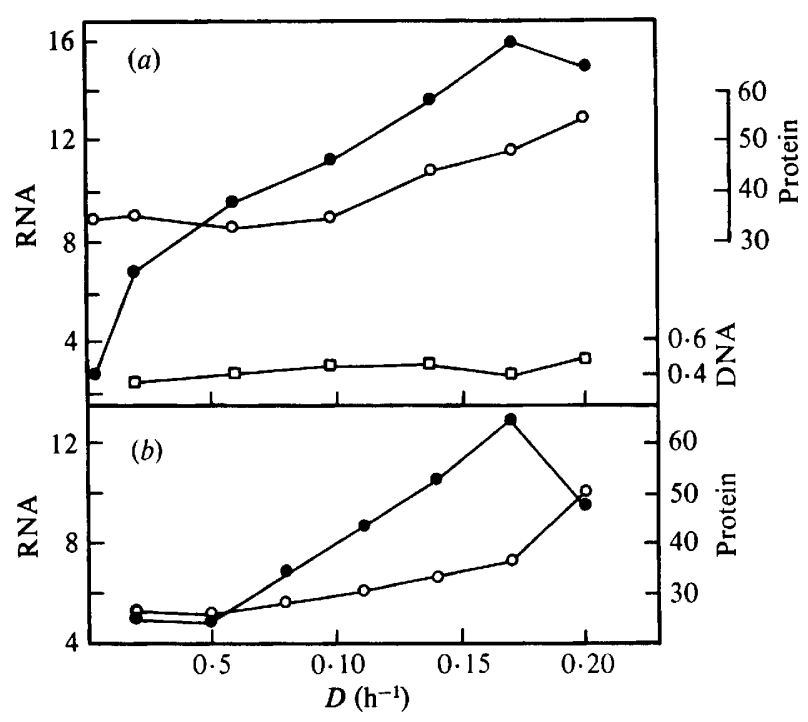

Fig. 6. Macromolecular composition of Trichoderma aureoviride (a) during glucose-limited growth and $(b)$ during ammonia-limited growth. RNA $(O)$, protein $(O)$ and DNA ( $\square)$. All values are expressed as a percentage of mycelial dry weight.

\section{Macromolecular composition}

The mycelial concentrations of RNA, DNA and protein for glucose-limited growth and of RNA and protein for ammonia-limited growth were measured over the range of dilution rates between $\mu_{\min }$ and $\mu_{\max }$ (Fig. $6 a, b$ ). The RNA concentration during glucose-limited growth was always higher than equivalent estimates made during ammonia limitation but under both limitations the maximum RNA contents were observed at about $0.8 \mu_{\max }$. Mycelial protein concentrations increased gradually as the dilution rate of glucose- and ammonia-limited chemostats was raised, although a sharp $20 \%$ increase was noted as $D$ approached $\mu_{\max }$ under ammonia limitation. Growth under glucose limitation always resulted in protein contents of about 5 to $15 \%$ greater than those observed at equivalent dilution rates during nitrogen-limited growth. Maximum protein concentrations (50 to $55 \%$ ) in both cases occurred as the dilution rate approached $\mu_{\max }$. In contrast to RNA and protein, the DNA concentration of glucose-limited mycelia was comparatively stable at approximately 0.4 to $0.5 \%$ dry weight over the dilution range studied. Calculations of the RNA efficiency in protein synthesis as a function of the dilution rate (Alroy \& Tannenbaum, 1973; McGetrick \& Bull, 1979) were made from the above data (Fig. 7).

\section{Cation composition}

Only two polyamines, spermidine and spermine, could be determined quantitatively during glucose-limited cultivation of $T$. aureoviride (Fig. $8 \mathrm{~b}$ ). However, a compound was detected that co-chromatographed with cadaverine, but its concentration was too low to permit its quantification. Spermidine was the major polyamine present at all growth rates and its concentration was markedly dependent upon the dilution rate. Spermine was present in much lower concentrations which did not show any obvious relationship to dilution rate. Extracellular polyamines were not detected under any conditions of carbon-limited growth.

The intracellular potassium concentration increased from about 250 to $550 \mu \mathrm{mol}$ ( $\mathrm{g}$ dry wt) $)^{-1}$ over the dilution rate range investigated (Fig. $8 a$ ). Magnesium concentrations also increased with dilution rate (Fig. $8 a$ ) from approximately 30 to $90 \mu \mathrm{mol}$ (g dry wt) ${ }^{-1}$ with most of this increase [about 50 to $90 \mu \mathrm{mol}$ (g dry wt) ${ }^{-1}$ ] occurring above $0 \cdot 14 \mathrm{~h}^{-1}$. 


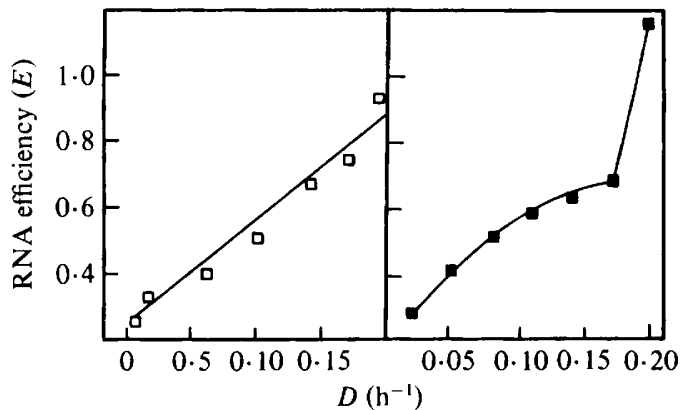

Fig. 7. The efficiency of RNA in protein synthesis $(E)$ during glucose-limited ( $\square$ ) and ammonia-limited (घ) growth of Trichoderma aureoviride. A linear regression analysis was used to fit the glucose-limited plot (regression coefficient, $0 \cdot 90$ ).

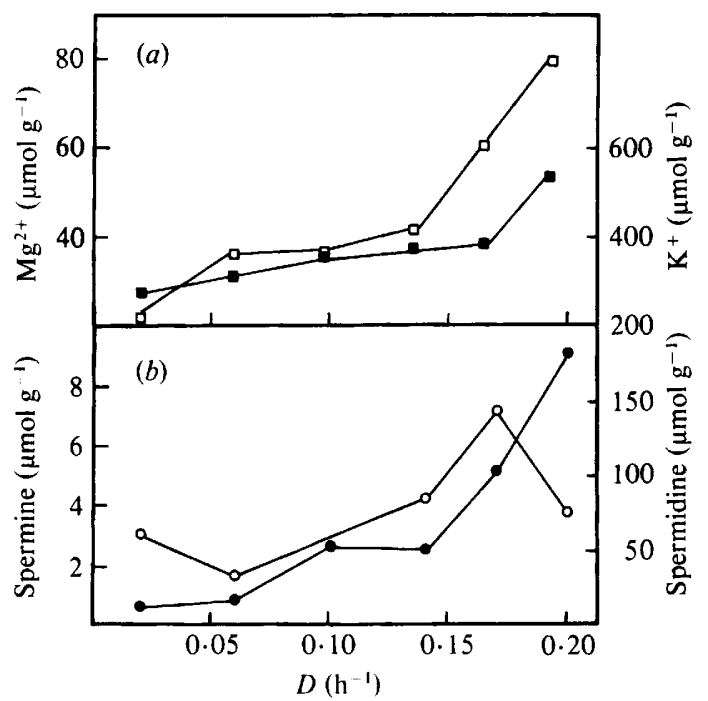

Fig. 8. Cation composition of Trichoderma aureoviride during glucose-limited growth: (a) magnesium $(\square)$, potassium ( $\square) ;(b)$ spermidine $(O)$, spermine (O).

Table 2. Molar ratios* of $R N A$, polyamines, $\mathrm{Mg}^{2+}$ and $\mathrm{K}^{+}$as functions of dilution rate in glucose-limited mycelia of Trichoderma aureoviride

$\begin{array}{ccccccc}\begin{array}{c}\text { Dilution rate } \\ \left(\mathrm{h}^{-1}\right)\end{array} & \text { RNA } & \mathrm{Mg}^{2+} & \mathrm{K}^{+} & \mathrm{Mg}^{2+} / \mathrm{K}^{+} & \text {Polyamines }{ }^{+} & \begin{array}{c}\text { Polyamines }+\mathrm{Mg}^{2+} / \\ \mathrm{RNA}\end{array} \\ 0.02 & 1 & 0.15 & 1.25 & 0.12 & 0.07 & 0.22 \\ 0.06 & 1 & 0.20 & 1.04 & 0.19 & 0.07 & 0.27 \\ 0.10 & 1 & 0.13 & 1.06 & 0.12 & 0.15 & 0.28 \\ 0.14 & 1 & 0.12 & 0.90 & 0.13 & 0.14 & 0.26 \\ 0.17 & 1 & 0.14 & 0.78 & 0.18 & 0.23 & 0.37 \\ 0.20 & 1 & 0.18 & 1.15 & 0.16 & 0.29 & 0.47\end{array}$

* Values for polyamines, $\mathrm{Mg}^{2+}$ and $\mathrm{K}^{+}$are expressed as molar ratios of the concentration of RNA which is standardized.

† Spermidine plus spermine. 
The molar ratios of $\mathrm{Mg}^{2+}, \mathrm{K}^{+}$, polyamine and $\mathrm{RNA}$ in glucose-limited mycelia are presented in Table 2. Although the molar concentrations of all of these constituents increased with increasing dilution rate, the molar ratio, RNA $: \mathrm{Mg}^{2+}: \mathrm{K}^{+}$appeared reasonably constant at approximately $8: 1: 8$. The polyamine concentration, on the other hand, increased relative to these other constituents as the dilution rate was increased and, relative to the RNA concentration, showed a maximum increase of approximately fourfold.

\section{I S C USS I ON}

The behaviour of $T$. aureoviride in chemostats is generally in agreement with that reported for the few other species of filamentous fungi studied in continuous-flow cultures (Bull \& Trinci, 1977). The biomass concentration profiles as a function of dilution rate are typical of carbon- and of nitrogen-limited micro-organisms (see, Herbert, 1961). It is reasonable to assume that the increasing biomass concentration with decreasing dilution rate under ammonia limitation is a reflection of carbon storage synthesis, probably glycogen and/or lipid, but we have not investigated the nature of such compounds. Of interest is the degree of morphological differentiation which occurred at low specific growth rates, a feature common among fungi. Such dilution rate-dependent heterogeneity may be responsible, in part, for the divergence of the experimental data and the calculated values for steady state biomass and limiting glucose concentrations (Fig. 1). This divergence is not fully accounted for by maintenance energy expenditure, particularly when $T$. aureoviride was growing at dilution rates less than $0.02 \mathrm{~h}^{-1}$ despite the fact that $38 \%$ of the glucose consumed is utilized for maintenance purposes at this dilution rate (Fig. 4). The equation for steady state limiting substrate concentration suggests three possible explanations for the disagreement between observed and calculated glucose concentrations: (1) catabolism of glucose continued during sample collection and manipulation, thereby producing falsely low values; (2) the value determined for the glucose saturation constant $\left(K_{\mathrm{S}}\right)$ was falsely high; or $(3)$ the value determined for the maximum specific growth rate $\left(\mu_{\max }\right)$ was falsely low.

The first explanation is extremely unlikely; samples were collected and inactivated in perchloric acid within approximately $1 \mathrm{~s}$ and it can be calculated from the steady state $q_{\text {glucose }}$ values that less than $0.1 \%$ of the glucose in the sample would be catabolized during this period. This also argues against an overestimate of the $K_{\mathrm{s}}$ being made. The $\mu_{\max }$ of glucose-limited T. aureoviride was determined from washout kinetics to be $0.22 \mathrm{~h}^{-1}$. Recently we have shown, via autoradiographic analysis, that the true specific growth rate of growing hyphae in chemostat culture $\left(\mu_{\mathrm{h}}\right)$ can be significantly higher than the apparent specific growth rate which, according to chemostat theory, is equivalent to the imposed dilution rate at steady state (Pitt \& Bull, 1982a). Consequently, the true maximum specific growth rate of $T$. aureoviride is underestimated by about $25 \%$ and the corrected value becomes $0.29 \mathrm{~h}^{-1}$. As shown in Fig. 1, use of this revised value of $\mu_{\max }$ produced calculated concentrations of the limiting substrate that are in very much closer accordance with the observed concentrations.

The minimum specific growth rate of $T$. aureoviride was judged to be approximately 0.03 $\mathrm{h}^{-1}$ under carbon- and nitrogen-limited conditions; this value is equivalent to $0 \cdot 10 \mu_{\max }$. Similar values of $\mu_{\min }$ have been estimated for Penicillium chrysogenum, $0 \cdot 13 \mu_{\text {max }}$ (Righelato, 1975) and $A$. nidulans, $0 \cdot 10 \mu_{\max }$ (McGetrick \& Bull, 1979). The significance of a minimum specific growth rate concept is strengthened when metabolic parameters complement morphogenetic changes. Thus, conidiation in chemostat populations of $P$. chrysogenum was accompanied with an increased rate of nucleic acid turnover and a decay in the specific rate of penicillin synthesis (Righelato et al., 1968). In A. nidulans the morphological definition of $\mu_{\min }$ has been correlated with a minimum efficiency of RNA in protein synthesis (Bull \& Trinci, 1977); in the present study $\mu_{\min }$ and RNA efficiency were not so correlated.

The maintenance energy coefficient for carbon-limited $T$. aureoviride was $0.02 \mathrm{~g}$ glucose (g biomass) $)^{-1} \mathrm{~h}^{-1}$, a value which is similar to that found for other filamentous fungi $(P$. 
chrysogenum, $0.022 \mathrm{~g} \mathrm{~g}^{-1} \mathrm{~h}^{-1}$, Righelato et al., 1968; A. nidulans, $0.029 \mathrm{~g} \mathrm{~g}^{-1} \mathrm{~h}^{-1}$, Carter et al., 1971; A. terreus $0.010 \mathrm{~g} \mathrm{~g}^{-1} \mathrm{~h}^{-1}$, Cylindrocarpon lichenicola, $0.038 \mathrm{~g} \mathrm{~g}^{-1} \mathrm{~h}^{-1}, \mathrm{~J}$. A. Rodriguez \& A. T. Bull, unpublished data). No systematic study has been made of the maintenance energy requirement and factors which control it in fungi. However, the available data suggest that, under optimal growth conditions, the maintenance requirement for filamentous fungi is remarkably constant (average about $25 \mathrm{mg}$ energy source per $\mathrm{g}$ biomass per $h$ ). Maintenance energy frequently constitutes a substantial proportion of the total energy consumed, the proportion clearly varying as a function of dilution rate in energy-limited systems (e.g. glucose-limited chemostat culture of $T$. aureoviride, Fig. 4). At dilution rates of about $0.02 \mathrm{~h}^{-1}, 30$ to $40 \%$ of the energy source may be diverted to mycelial maintenance (Bull \& Trinci, 1977; this paper) but when the dilution rate is $0.005 \mathrm{~h}^{-1}$, as much as $70 \%$ of the energy source is required for maintenance functions (Righelato et al., 1968). A supply of 1.7 to 3 times the maintenance ration of glucose to a fed-batch culture of $T$. aureoviride (Fig. 5) was sufficient to ensure continued biomass synthesis at a quasi-steady state rate of 0.027 $\mathrm{h}^{-1}$. Nevertheless, these rates of energy source supply were insufficient to maintain the biomass in an undifferentiated mycelial form. Bainbridge et al. (1971) found that supplying the energy source at 1.5 times the maintenance ration to fed-batch cultures of $A$. nidulans did not allow net biomass synthesis but maintained the biomass concentration at $80 \%$ of its initial value; under these conditions hyphal vacuolation and partial autolysis occurred together with some conidia production.

The environmental control of chemical composition of fungi, other than yeasts, has received scant attention and in particular very few chemostat data have been reported. Over most of the growth rate range examined the RNA and protein patterns of glucose- and ammonia-limited $T$. aureoviride were very similar although the respective maximum concentrations were 30 and $40 \%$ lower under nitrogen limitation. Such dilution rate dependent change in RNA content is similar to that originally reported by Herbert (1961) for bacteria. The decline in RNA content at the highest dilution rate analysed is not understood. The RNA content of $T$. aureoviride mycelium is higher than most values quoted for filamentous fungi (e.g. Griffin et al., 1974; McGetrick \& Bull, 1979) and, in part, is probably due to the rapid quenching and analysis of culture samples; RNA degradation in stored material is known to occur at significant rates (Herbert et al., 1971). The lower RNA content under nitrogen-limited cultivation contrasts with Herbert's (1961) data for bacterial composition and the difference between our carbon- and nitrogen-limited data is only partly accounted for in terms of an increased proportion of carbon storage materials under the latter condition at low $D$ (i.e. $<0 \cdot 125 \mathrm{~h}^{-1}$ ); cf. Figs 1 and 2.

The DNA content of $T$. aureoviride was independent of dilution rate, a response which has been noted in other fungi such as Gibberella fujikuroi (Bu'Lock et al., 1974) and A. nidulans (McGetrick \& Bull, 1979). The ratio of RNA to DNA maintained a linear relationship to dilution rate at all except very low values $\left(D<0.05 \mathrm{~h}^{-1}\right)$, an observation which is consistent with an increasing rate of transcription per stable DNA cistron (Smith, 1979).

Previous determinations of the efficiency of RNA in fungal protein synthesis (g protein synthesized per g RNA per h) (Alroy \& Tannenbaum, 1973) have been few but available data suggest that maximum efficiencies are attained at dilution rates equivalent to 65 to $80 \% \mu_{\max }$ under energy limitation (Bull \& Trinci, 1977). Such findings have been interpreted as implying that all ribosomes and ribosomal subunits are associated in functional polysomal complexes even when growth is substantially below the maximum specific rate. The exact relationship between efficiency and dilution rate shows variation: Alroy \& Tannenbaum's (1973) early studies with yeast revealed a linear relationship which extrapolated to the origin whereas in highly sporulating populations of $A$. nidulans zero efficiency was extrapolated to a dilution rate equivalent to $\mu_{\min }$ (Bushell \& Bull, 1976). In the current work with $T$. aureoviride the dilution rate dependence of efficiency was different under glucose and ammonia limitation. Under glucose limitation the relationship was reasonably linear $(r=0.90)$ over the whole 
range of $D$. Efficiency appeared to reach a plateau at $D=0.17 \mathrm{~h}^{-1}\left(77 \% \mu_{\text {max }}\right)$ under ammonia limitation then rose sharply at $D=0.20 \mathrm{~h}^{-1}$ under which condition ammonia limitation was largely relieved (Fig. 2). These observations suggest that maximum translational capacity in $T$. aureoviride was controlled by the nature, as well as the availability, of the growth-limiting substrate.

The mycelial content of magnesium increased with dilution rate but the molar ratio of $\mathrm{Mg}^{2+}$ to RNA remained fairly constant at 1:8 (Table 2). These findings point to a role for $\mathrm{Mg}^{2+}$ in ribosome stabilization and are consistent with data obtained from bacteria (Tempest, 1969) and Candida utilis (Aiking \& Tempest, 1976). In contrast to $T$. aureoviride, the $\mathrm{Mg}^{2+}$ : RNA molar ratio of carbon-limited mycelia of $A$. nidulans varied with dilution rate. The potassium content of Trichoderma mycelia was much higher than that of magnesium and it occurred in a 1:1 molar ratio with RNA. Although $\mathrm{K}^{+}$is also associated with ribosomes in growing micro-organisms its concentration in $T$. aureoviride seems to be in far excess of this requirement and its primary role may be related to glucose utilization. Previous studies with Neurospora crassa (Viotti et al., 1971) and A. nidulans (Bushell \& Bull, 1974) have led to the postulate that a degree of functional interchangeability between $\mathrm{Mg}^{2+}$ and polyamines may occur in the regulation of RNA stability and synthesis. Glucose-limited cultures of the latter fungus produced mycelia in which the molar ratio of $\mathrm{Mg}^{2+}$ plus total polyamines:RNA remained constant irrespective of the imposed dilution rate. This relationship was not a feature of $T$. aureoviride growth (Table 2) where, instead, the molar ratio of $\mathrm{Mg}^{2+}$ plus polyamines: RNA rose progressively as $D$ was increased.

We thank the University of Wales Institute of Science and Technology for the award of a Research Studentship to D.E.P. and Dr L. A. Anderson (Welsh School of Pharmacy) for help in optimizing procedures for the separation of polyamines.

\section{REFERENCES}

AIKING, H. \& Tempest, D. W. (1976). Growth and physiology of Candida utilis NCYC 321 in potassium-limited chemostat culture. Archives of Microbiology 108, 117-124.

Allen, S. E., Grimshaw, H. M., Parkinson, J. A. \& QuarmbY, C. (1974), Chemical Analyses of Ecological Materials. Oxford: Blackwell Scientific Publications.

Alroy \& Tannenbaum, S. R. (1973). The influence of environmental conditions on the macromolecular composition of Candida utilis. Biotechnology and Bioengineering 15, 239-256.

Bainbridge, B. W., Bull, A. T., Pirt, S. J., Rowley, B. I. \& Trincl, A. P. J. (1971). Biochemical and structural changes in non-growing maintained and autolysing cultures of Aspergillus nidulans. Transactions of the British Mycological Society 56, 371-385.

Bull, A. T. \& Trincl, A. P. J. (1977). The physiology and metabolic control of fungal growth. Advances in Microbial Physiology 15, 1-84.

Bu'Lock, J. D., Detroy, R. W., Hostalek, Z. \& MUNim-AL-ShaKARCHI, A. (1974). Regulation of secondary biosynthesis in Gibberella fujikuroi. Transactions of the British Mycological Society 62 , 377-389.

Bushell, M. E. \& Bull, A. T. (1974). Polyamine, magnesium and ribonucleic acid levels in steady state cultures of the mould Aspergillus nidulans. Journal of General Microbiology 81, 271-273.

Bushell, M. E. \& BulL, A. T. (1976). Growth rate dependent ribosomal efficiency of protein synthesis in the fungus Aspergillus nidulans. Journal of Applied Chemistry and Biotechnology 26, 261.

Carter, B. L. A. \& Bull, A. T. (1969). Studies of fungal growth and intermediary carbon metabolism under steady and non-steady state conditions. Biotechnology and Bioengineering 11, 785-804.

Carter, B. L. A., Bull, A. T., Pirt, S. J. \& Rowley, B. I. (1971). Relationship between energy substrate utilization and specific growth rate in Aspergillus nidulans. Journal of Bacteriology 108, 309-313.

Chesters, C. G. C. \& Bull, A. T. (1963). The enzymic degradation of laminarin. Biochemical Journal 86, 28-46.

Dion, A. S. \& Herbst, E. J. (1970). Polyamine changes during the development of Drosophila melanogaster. Annals of the New York Academy of Sciences 171, 723-734.

Griffin, D. H., Timberlake, W. E. \& Cheney, J. C. (1974). Regulation of macromolecular synthesis, colony development, and specific growth rate of Achlya bisexualis during balanced growth. Journal of General Microbiology 80, 381-388.

HerberT, D. (1961). The chemical composition of micro-organisms as a function of their environment. Symposia of the Society for General Microbiology 11, 391-416.

Herbert, D., Phipps, P. J. \& Strange, R. E. (1971). Chemical analysis of microbial cells. Methods in Microbiology 5B, 209-344.

JANNASCH, H. W. (1969). Estimations of bacterial growth rates in natural waters. Journal of Bacteriology 99, 156-160. 
McGetrick, A. M. T. \& Bull, A. T. (1979). Phenotypic changes in the chemistry of Aspergillus nidulans: influence of culture conditions on mycelial composition. Archives of Microbiology 123, 151156.

PIRT, S. J. (1975). Principles of Microbe and Cell Cultivation. Oxford: Blackwell Scientific Publications.

PitT, D. E. \& Bull, A. T. $(1982 a)$. Use of autoradiography to quantify aspects of fungal growth and starvation in submerged liquid culture. Transactions of the British Mycological Society 78. 97-104.

PitT, D. E. \& Bull, A. T. $(1982 b)$. The adenine nucleotide composition of growing and stressed cultures of Trichoderma aureoviride. Experimental Mycology 6, (in the Press).

RifAI, M. A. (1969). A revision of the genus Trichoderma. Mycological Paper No. 116. Kew: Commonwealth Mycological Institute.

Righelato, R. C. (1975). Growth kinetics of my- celial fungi. In The Filamentous Fungi I, pp. 79-103. Edited by J. E. Smith \& D. R. Berry. London: Edward Arnold.

Righelato, R. C., Trinci, A. P. J., Pirt, S. J. \& PeAt, A. (1968). The influence of maintenance energy and growth rate on the metabolic activity, morphology and conidiation of Penicillium chrysogenum. Journal of General Microbiology 50, 399412.

SMITH, R. J. (1979). Increasing guanosine $3^{\prime}$-diphosphate $5^{\prime}$-diphosphate concentration with decreasing growth rate in Anacystis nidulans. Journal of General Microbiology 113, 403-405.

TEMPEST, D. W. (1969). Quantitative relationships between inorganic cations and anionic polymers in growing bacteria. Symposia of the Society for General Microbiology 19, 87-111.

Viotti, A., Bagni, N., Struani, E. \& Alberghina, F. A. M. (1971). Magnesium and polyamine levels in Neurospora crassa mycelia. Biochimica et biophysica acta 244, 329-337. 